BIOSFER: JURNAL PENDIDIKAN BIOLOGI (BIOSFERJPB)

2017, volume 10 No $1,1-8$

ISSN: 0853-2451

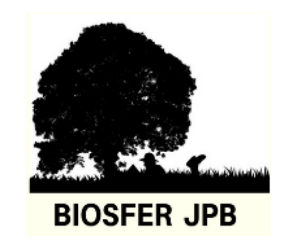

\title{
PENGEMBANGAN PRAKTIKUM VIRTUAL URINALISIS SEBAGAI MEDIA PEMBELAJARAN BIOLOGI SISWA SMA KELAS XI
}

\section{Development Virtual Lab Work of Urinalysis as a Learning Media of Biology for Senior High School Grade XI}

\author{
Ade Suryanda, Rusdi, Dewi Kusumawati \\ Pendidikan Biologi, Fakultas MIPA, Universitas Negeri Jakarta \\ Email: adesuryanda@yahoo.com
}

\begin{abstract}
Lab work has become one of the most important activities in learning Biology. Urinalysis requires special treatment because urinalysis using urine as a sample to be analyzed. There have been limitations in implementation of the lab work of urinalysis at high school level. Learning media such as virtual lab work of urinalysis was expected to overcome the limitations. The aim of this research was to develop virtual lab work as learning media of Biology. The research was held at Senior High School 4 Tangerang, using research and development method. Research and information collecting, planning, product development, and try-out and revision were the steps in this research. Instrumen used were questionnaires for need assessment for students, interviews guide for Biology teacher, and questionnaires of feasibility for media expert, material expert, Biology teacher, and students. In the try-out and revision steps, media expert and material expert were involved in feasibility testing, meanwhile Biology teacher and students grade XI at Senior High School 4 Tangerang were involved in field testing. The average percentage of all test products scored $81,76 \%$. The result of this research showed that the virtual lab work of urinalysis could be utilized as one of learning media of Biology for Senior High School grade XI.
\end{abstract}

\section{Keywords: Learning media, virtual lab work, urinalysis}

\section{PENDAHULUAN}

Cain dan Evans (dalam Rustaman et al., 2003) menyatakan bahwa untuk dapat memahami sains secara utuh, siswa perlu mengalami empat hal yang terkandung didalamnya yaitu konten atau produk, proses atau metode, sikap, dan teknologi. Biologi termasuk dalam sains sehingga dalam memahaminya, siswa tidak hanya mempelajari produk saja, tetapi juga aspek proses, sikap, dan teknologinya. Ketiga aspek tersebut dalam pembelajaran Biologi dapat diperoleh dari kegiatan eksperimen di laboratorium atau disebut juga kegiatan praktikum.

Namun faktanya, pelaksanaan kegiatan praktikum di SMA seringkali menemui kendala. Beberapa kendalanya antara lain kondisi laboratorium Biologi yang masih bergabung dengan laboratorium Fisika dan Kimia, laboratorium yang beralih fungsi sebagai ruang kelas, keterbatasan alat dan bahan praktikum di laboratorium, dan kesulitan siswa dalam memahami prosedur kerja praktikum (Hamidah et al., 2014). 
Berdasarkan hasil wawancara guru Biologi, didapatkan fakta bahwa terdapat kegiatan persiapan sebelum praktikum dilaksanakan. Meskipun kegiatan persiapan praktikum sudah dilakukan, tetapi siswa masih kesulitan dan keliru dalam melakukan cara kerja saat praktikum. Hal ini disebabkan karena kegiatan persiapan praktikum masih berpusat pada guru sehingga siswa tidak berperan secara aktif pada kegiatan tersebut. Hasil penelitian Khamida dan Aprilia (2014) juga menyebutkan bahwa peran siswa saat kegiatan persiapan praktikum masih tergolong rendah. Alternatif yang dapat dilakukan untuk mengatasi hal tersebut adalah mengembangkan media pembelajaran yang dapat memberikan gambaran atau simulasi kegiatan praktikum secara interaktif sehingga siswa dapat berperan aktif dalam proses persiapan praktikum.

Melihat karakteristik siswa berdasarkan hasil analisis kebutuhan, didapatkan fakta bahwa siswa terbiasa menggunakan komputer, dengan rata-rata pemakaian \pm 3 kali dalam seminggu. Selain itu, guru Biologi juga terbiasa menggunakan komputer dalam proses pembelajaran. Berdasarkan fakta tersebut, maka pengembangan media pembelajaran berupa simulasi kegiatan praktikum dapat dibuat menggunakan teknologi komputer dalam bentuk virtual. Penggunaan media pembelajaran berupa praktikum secara virtual dapat dijadikan strategi pembelajaran yang memanfaatkan keterampilan alami siswa. Pemanfaatan teknologi untuk kepentingan pembelajaran bukan lagi menjadi hal yang baru, apalagi di era digital seperti saat ini. Teknologi virtual dapat mendukung pengalaman belajar sehingga direkomendasikan penggunaannya dalam berbagai disiplin ilmu, termasuk pendidikan (Hanson \& Shelton, 2008).

Praktikum virtual dapat digunakan sebagai media pembelajaran mandiri untuk siswa kelas XI (Mahdini et al., 2014). Salah satu materi kelas XI yang dapat diaplikasikan adalah sistem urinaria. Materi sistem urinaria didukung dengan kegiatan praktikum uji urin atau urinalisis. Praktikum urinalisis dapat memfasilitasi siswa mencapai kompetensi yang diharapkan. Praktikum urinalisis mengarahkan siswa untuk menganalisis kelainan pada struktur dan fungsi organ serta menjelaskan gangguan fungsi yang terjadi pada sistem urinaria melalui pengamatan dan percobaan terhadap sampel urin. Selain itu, siswa juga dapat mengidentifikasi karakteristik urin normal, serta membuktikan beberapa senyawa yang secara normal ditemukan pada urin dan senyawa lain yang tidak boleh terkandung dalam urin.

Praktikum urinalisis menggunakan urin sebagai sampel untuk diuji. Urin memerlukan perlakuan khusus untuk menghindari terjadinya kesalahan saat pemeriksaan agar dapat diperoleh hasil yang sesuai dengan kondisi klinisnya (Almahdaly, 2012). Hal ini pula yang menjadi alasan kegiatan praktikum urinalisis terhitung jarang dilakukan di sekolah. Praktikum virtual urinalisis dapat menyajikan simulasi praktikum urinalisis untuk sekolah yang tidak melaksanakan praktikum urinalisis. Selain itu, simulasi tersebut juga dapat memberikan panduan untuk siswa mengenai cara kerja praktikum urinalisis dan hal-hal yang perlu diperhatikan saat pemeriksaan urin, serta membantu guru pada proses persiapan praktikum untuk sekolah yang melaksanakan kegiatan praktikum urinalisis.

Penelitian ini bertujuan untuk mengembangkan praktikum virtual urinalisis sebagai media pembelajaran Biologi siswa SMA kelas XI. Media pembelajaran hasil penelitian dan pengembangan ini dapat digunakan Sebagai media pembelajaran yang dapat digunakan siswa pada proses persiapan praktikum urinalisis, sebagai salah satu alternatif pilihan media 
pembelajaran Biologi yang dapat digunakan guru untuk memberikan simulasi praktikum urinalisis, hasil dari penelitian ini dapat dikembangkan untuk penelitian selanjutnya.

\section{METODE}

Penelitian ini dilaksankan pada bulan Februari-Juni 2016. Subjek penelitian ini adalah siswa kelas XI MIA dan guru Biologi kelas XI MIA di SMAN 4 Tangerang. Metode yang digunakan dalam penelitian ini adalah metode penelitian dan pengembangan (Research and Development). Langkah dalam penelitian ini adalah melakukan penelitian dan pengumpulan informasi, merencanakan produk, mengembangkan produk, dan menyempurnakan produk melalui berbagai uji dan revisi.

\section{HASIL DAN PEMBAHASAN}

Hasil penelitian dapat digabung dengan pembahasan menjadi bab Hasil dan Pembahasan. Pemisahan atau penggabungan kedua bagian ini bergantung pada keadaan data dan kedalaman pembahasannya sesuai dengan arahan pembimbing. Bila Hasil dan Pembahasan disatukan dalam satu bab, sajikan dahulu hasil penelitian, beri penjelasan yang cukup untuk temuan penting, lanjutkan dengan analisis dan kemudian dengan pembahasan. Subbab dalam Hasil dan Pembahasan dikembangkan secara sistematis dan mengarah ke simpulan.

\section{Hasil}

Hasil uji kelayakan oleh ahli media mendapat skor akhir sebesar 78,90\%. Skor tiap komponen penilaian ahli media dapat dilihat pada Gambar 1 di bawah ini:

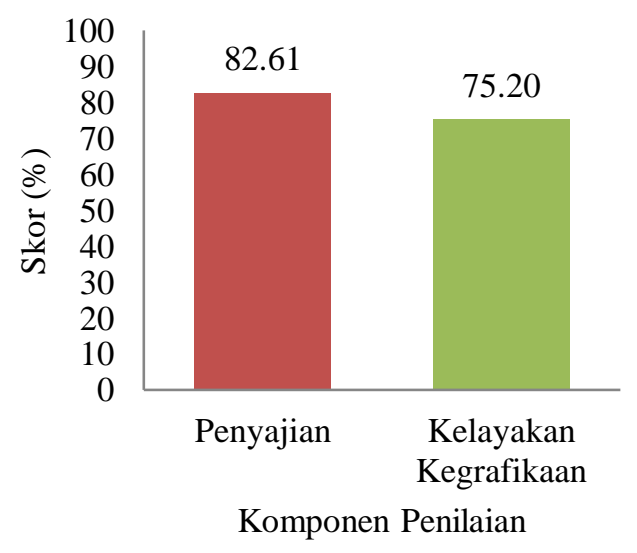

Gambar 1. Hasil Uji Kelayakan Ahli Media

Hasil uji kelayakan oleh ahli materi mendapat skor akhir sebesar 86,86\%. Skor tiap komponen penilaian ahli materi dapat dilihat pada Gambar 2 di bawah ini: 


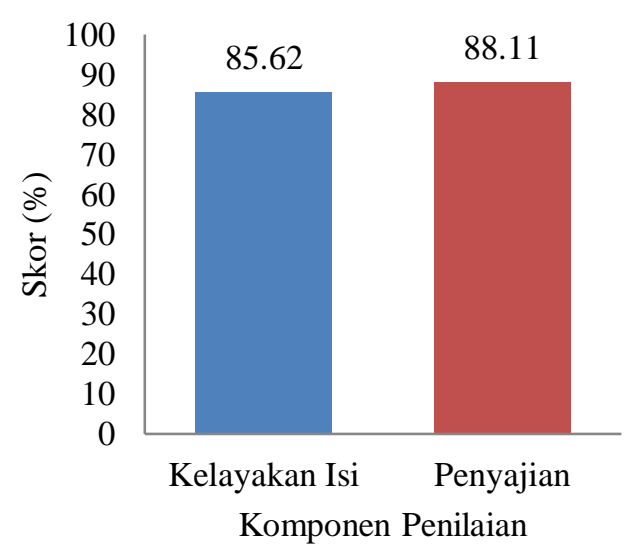

Gambar 2. Hasil Uji Kelayakan Ahli Materi

Hasil uji coba pada guru Biologi mendapat skor akhir sebesar 81,94\%. Skor tiap komponen penilaian guru Biologi dapat dilihat pada Gambar 3 di bawah ini:

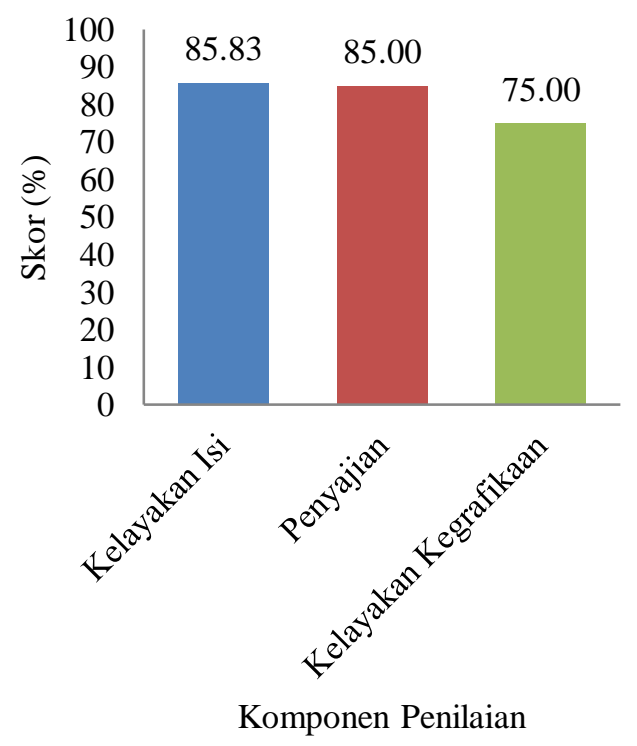

Gambar 3. Hasil Uji Coba pada Guru Biologi

Hasil uji coba pada siswa mendapat skor akhir sebesar 77,92\%. Skor tiap komponen penilaian uji lapangan awal dapat dilihat pada Gambar 4 di bawah ini: 


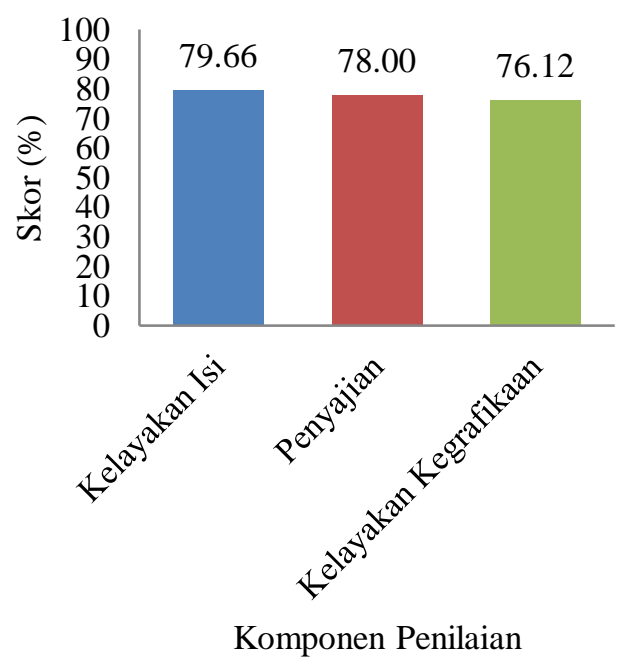

Gambar 4. Hasil Uji Coba Lapangan Awal

Hasil uji coba pada siswa mendapat skor akhir sebesar 73,20\%. Skor tiap komponen penilaian uji lapangan utama dapat dilihat pada Gambar 5 di bawah ini:

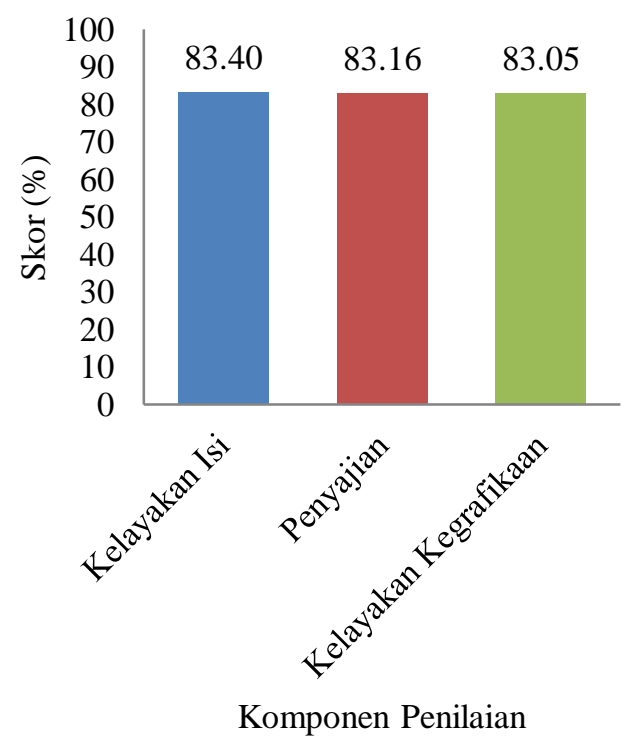

Gambar 5. Hasil Uji Coba Lapangan Utama

\section{Pembahasan}

Uji kelayakan oleh ahli media mendapat rata-rata skor tertinggi $(93,33 \%)$ pada sub komponen pemberian motivasi dan daya tarik. Hal ini membuktikan bahwa media pembelajaran yang dibuat telah memenuhi salah satu fungsi utamanya sebagai media pembelajaran, dimana disebutkan Kemp dan Dayton dalam Kustandi dan Sutjipto (2011) bahwa salah satu fungsi utama dari media pembelajaran adalah memotivasi minat dan 
tindakan siswa.

Uji kelayakan oleh ahli media mendapat rata-rata skor terendah $(70,00 \%)$ pada sub komponen suara. Penilaian ini didapatkan karena pada musik latar pada aplikasi memiliki volume yang cukup keras dan tidak terdapat pengatur volume yang memungkinkan pengguna untuk mengatur besar kecilnya suara pada media. Media hasil teknologi komputer seharusnya dapat digunakan sesuai keinginan pengguna. Hal ini berkaitan dengan ciri media hasil teknologi komputer (Kustandi \& Sutjipto, 2011). Perbaikan yang dilakukan adalah dengan menurunkan volume musik latar agar tidak mengganggu konsentrasi pengguna saat menggunakan media pembelajaran.

Uji kelayakan oleh ahli materi mendapat rata-rata skor tertinggi $(90,00 \%)$ pada 6 sub komponen, antara lain kesesuaian dengan perkembangan media pembelajaran, akurasi substansi pada media pembelajaran, gambaran umum, kualitas teknis aplikasi, pemberian motivasi dan daya tarik, serta interaktivitas. Hal ini membuktikan bahwa secara umum media memiliki interpretasi baik dari hasil penilaian ahli materi.

Uji kelayakan oleh ahli materi mendapat rata-rata skor terendah $(75,00 \%)$ pada sub komponen kesesuaian dengan kurikulum. Hal ini disebabkan karena pada media belum dicantumkan kompetensi yang harus dicapai siswa setelah melaksanakan praktikum urinalisis. Siswa perlu mengetahui kompetensi yang dicapai karena hal ini terkait dengan berbagai kondisi dan prinsip-prinsip psikologis yang perlu dipertimbangkan dalam pemilihan dan penggunaan media, salah satunya adalah kompetensi yang diharapkan (Kustandi \& Sutjipto, 2011). Perbaikan yang dilakukan adalah dengan menambahkan kompetensi yang harus dicapai oleh siswa dalam pelaksanaan praktikum urinalisis.

Uji coba pada guru Biologi mendapat rata-rata skor tertinggi $(90,00 \%)$ pada 4 sub komponen, yaitu kesesuaian dengan perkembangan materi pembelajaran, gambaran umum, kelengkapan informasi, dan teks. Hal ini membuktikan bahwa secara umum media memiliki interpretasi baik dari hasil penilaian guru Biologi.

Uji coba pada guru Biologi mendapat rata-rata skor terendah $(70,00 \%)$ pada 3 sub komponen yaitu ilustrasi, tampilan, dan suara. Penilaian tersebut didapatkan karena menurut penilaian guru Biologi, media pembelajaran kurang memperhatikan detail alat dan bahan praktikum. Terdapat penggabungan alat praktikum yaitu tabung reaksi dengan rak tabung reaksi. Penggabungan beberapa alat menjadi satu kesatuan merupakan salah satu bentuk efisiensi proses pada pengembangan dan penggunaan media pembelajaran. Hal ini juga didukung dengan ciri media pembelajaran yang dikemukakan Gerlach dan Ely dalam Arsyad (2014) yaitu media memungkinkan untuk manipulasi objek sesuai dengan keinginan pengembang dan kemudahan pengguna.

Uji lapangan awal mendapat rata-rata skor tertinggi $(82,00 \%)$ pada sub komponen keterbacaan. Hal ini disebabkan karena media pembelajaran dibuat dengan mempertimbangkan tingkat berpikir siswa sehingga menggunakan bahasa yang mudah dipahami. Uji lapangan awal mendapat rata-rata skor terendah $(75,00 \%)$ pada sub komponen teks dan tampilan. Hal ini disebabkan karena warna pada beberapa komponen tampilan, khususnya hasil pemeriksaan pada detail praktikum kurang kontras sehingga menyulitkan siswa dalam membedakan.

Uji lapangan utama mendapat rata-rata skor tertinggi $(85,80 \%)$ pada sub komponen pemberian motivasi dan daya tarik. Media pembelajaran dapat menarik perhatian siswa dan memungkinkan siswa mendapatkan pengalaman belajar yang bervariasi. Hal ini berkaitan 
dengan manfaat media pembelajaran dalam proses belajar yang dialami siswa (Sudjana \& Rivai, 2013).

Uji lapangan utama mendapat rata-rata skor terendah $(79,40 \%)$ pada sub komponen teknik penyajian praktikum virtual. Hal ini disebabkan karena pada media pembelajaran tidak terdapat pengaturan urutan praktikum yang harus dilakukan oleh siswa. Berbagai tema praktikum dengan 10 jenis pilihan pemeriksaan maupun pengujian pada praktikum urinalisis yang terdapat pada media pembelajaran dapat secara bebas dipilih oleh siswa. Fleksibilitas tersebut dibuat dengan didasarkan kepada karakteristik media hasil teknologi komputer yang dapat digunakan secara acak (Kustandi \& Sutjipto, 2011).

Dari hasil pengujian lapangan awal dan utama diketahui bahwa setiap komponen mengalami kenaikan skor rata-rata karena telah dilakukan berbagai perbaikan untuk menyempurnakan produk. Pada tahap uji coba lapangan utama, peneliti juga melakukan pengambilan data tambahan berupa pretest dan post test kepada siswa sebelum dan setelah menggunakan media. Hal ini bertujuan untuk melihat penerapan praktikum virtual urinalisis sebagai media pembelajaran Biologi. Hasil yang didapatkan dari nilai pretest dan post test menunjukan kenaikan nilai sebesar $11,05 \%$, dengan rata-rata nilai pretest sebesar 85,09 dan rata-rata nilai post test 94,50 . Siswa yang mengalami kenaikan nilai sebanyak $55,88 \%$. Siswa yang nilainya tetap sebanyak $38,24 \%$. Siswa yang mengalami penurunan nilai sebanyak $5,88 \%$.

Untuk menilai kelayakan dari aplikasi praktikum virtual urinalisis sebagai media pembelajaran Biologi siswa SMA kelas XI dilakukan dengan merata-ratakan persentase skor dari lima uji yaitu uji kelayakan ahli media dan ahli materi, serta uji coba pada guru Biologi, uji lapangan awal dan uji lapangan utama. Rata-rata persentase yang didapatkan adalah $81,76 \%$. Dengan demikian, aplikasi praktikum virtual urinalisis telah layak dijadikan media pembelajaran Biologi.

Praktikum virtual urinalisis ini memiliki kelebihan antara lain terdapat materi urinalisis sebelum masuk pada proses praktikum, mencakup beberapa pemeriksaan dan pengujian yang dilakukan di sekolah maupun yang tidak dilakukan di sekolah, tampilan dibuat mendekati bentuk asli mulai dari dekorasi, tata letak atau penempatan, alat dan bahan, hingga proses detail praktikum. Namun praktikum virtual urinalisis ini juga masih memiliki kekurangan dan keterbatasan diantaranya masih terdapat kesalahan proses (bug atau error) pada beberapa proses detail praktikum, dan komponen suara yang digunakan baru sebatas suara latar dan efek suara, belum ada panduan pada media dalam berbentuk narasi.

\section{SIMPULAN}

Praktikum virtual urinalisis sebagai media pembelajaran Biologi telah berhasil dikembangkan dan memperoleh nilai interpretasi sangat layak. Dapat disimpulkan bahwa media ini dapat digunakan sebagai salah satu variasi media pembelajaran pada mata pelajaran Biologi untuk siswa SMA kelas XI.

\section{DAFTAR PUSTAKA}

Almahdaly, H. (2012). Pengaruh Penundaan Waktu Terhadap Hasil Urinalisis Sedimen Urin. Makasar: Fakultas Farmasi Universitas Hasanuddin.

Arsyad, A. (2014). Media Pembelajaran. Jakarta: Rajawali Pers. 
Hamidah, A., Sari, E. N., \& Budianingsih, R. S. (2014). Persepsi Siswa tentang Kegiatan Praktikum Biologi di Laboratorium SMA Negeri Se-Kota Jambi. Jurnal Sainmatika, 8(1), 49-59.

Hanson, K., \& Shelton, B. E. (2008). Design and Development of Virtual Reality: Analysis of Challenges Faced by Educator. Educational Technology \& Society, 11(1), 118-131.

Khamida, N., \& Aprilia, N. (2014). Evaluasi Program Pelaksanaan Praktikum Biologi Kelas XI SMA Se-Kecamatan Umbulharjo Yogyakarta Semester II Tahun Ajaran 2013/2014. JUPEMASI-PBIO, 1(1), 5-8.

Kustandi, C., \& Sutjipto, B. (2013). Media Pembelajaran Manual dan Digital. Bogor: Penerbit Ghalia Indonesia.

Mahdini, S., Yelianti, U., \& Budiarti. R. S. (2014). Pengembangan Media Pembelajaran Laboratorium Virtual pada Materi Uji Zat Makanan untuk Siswa Kelas XI SMA.http://103.26.102.47/eskripsi/data/pdf/jurnal_mhs/artikel/A1C409 008.pdf

Rustaman, N. Y., Dirdjosoemarto, S., Yudianto, S. A., Achmad, Y., Subekti, R., Rochintaniawati, D., \& Nurjhani, M. (2003). Strategi Belajar Mengajar Biologi. Bandung: JICA.

Sudjana, N., \& Rivai, A. (2013). Media Pengajaran. Bandung: Sinar Baru Algesindo. 